\title{
Primary teachers' first aid management of children's school day accidents: Video-assisted teaching method versus lecture method
}

\author{
Jaklein R.Younis *1, Amal El-Abassy ${ }^{2}$ \\ ${ }^{1}$ Pediatric Nursing Department, Faculty of Nursing, Menoufia University, Menoufia, Egypt \\ ${ }^{2}$ Community Health Nursing Department, Faculty of Nursing, Menoufia University, Menoufia, Egypt
}

Received: March 4, 2015

DOI: $10.5430 /$ jnep.v5n10p60

\author{
Accepted: June 28, 2015 \\ Online Published: July 27, 2015 \\ URL: http://dx.doi.org/10.5430/jnep.v5n10p60
}

\begin{abstract}
Background: First aid is the initial care for ill and injured. It helps to urgently manage the health problems of school age children. Therefore, teaching first aids should be compulsory in all schools through advanced methods of teaching strategies. Aim: the current study was conducted to determine the effect of video assisted teaching method versus traditional lecture on primary teachers' knowledge and skills regarding first aids management of children's school day accidents.

Methods: A Comparative research design was used for this study. Sample: simple random sample of 200 primary school teachers was included. Settings: the study was carried out at four primary schools in Shebin-Elkom town and ELShohadaa town, Menoufia Governorate. Tools: two tools were used for data collection. Tool one: teachers' knowledge questionnaire: it consisted of two parts. (a) A structured: socio-demographic questionnaire to obtain demographic data of the studied subjects; (b) Structured knowledge questionnaire regarding first aids measures. Tool two: five points Likert- scale structured performance check list was used to assess degree of improvement in primary school teachers' management skills regarding first aids for children' school day accidents after utilization of Video-assisted teaching method versus Lecture Method.

Results: The study showed a statistical significant improvement in total knowledge score of primary school teachers undergoing video-assisted teaching method regarding first aids of children' school day accidents (28.68 \pm 3.77$)$ compared to teachers undergoing traditional lecture $(12.77 \pm 5.00)$. Also, there was statistical significant improvement in management skills of primary school teachers undergoing video-assisted teaching method $(28.68 \pm 3.77)$ compared to teachers undergoing traditional lecture. Conclusions: Utilization of video-assisted teaching method was succeeded in achieving significant improvements in the primary school teachers' knowledge and skills regarding first aid of children's school day accidents compared to traditional lecture method. Recommendations: importantly utilizing video-assisted teaching strategy in teaching first aid to promote children's health and improve knowledge and management skills of their caregivers.
\end{abstract}

Key Words: First aid, Video-assisted teaching method, Traditional lecture

\section{INTRODUCTION}

Children injuries are growing global public health problems. Thousands of children die each year from injuries or violence, and millions suffer the consequences of non-fatal injuries. ${ }^{[1]}$ In Egypt, 2009, more than 746,000 injured cases were registered in to the Ministry of Health hospitals. Around $38 \%$ of

*Correspondence: Jaklein R.Younis; Email: rjaklein@yahoo.com; Address: Pediatric Nursing Department, Faculty of Nursing, Menoufia University, Menoufia, Egypt. 
all injuries occur among children and young adults less than 20 years of age. Furthermore, more than 20,000 people lose their life due to injuries every year, accounting for nearly 1 out of every 10 deaths globally. ${ }^{[2]}$ The most common injuries, whether intentional or non-intentional, include road traffic injuries, drowning, falls, suicide and homicide. Injuries are one of the most leading causes of childhood death and significantly contribute to cause childhood morbidity, long-term disability, and increase healthcare costs in most industrialized countries. ${ }^{[3]}$ Early and appropriate treatment of such emergencies can help reduce morbidity and mortality through first aid measures. ${ }^{[4]}$

Studies have been emphasized that administering appropriate first aid to students soon after the injuries or unexpected illnesses can be lifesaving. In that case proficient and skillful first aid mangers are a priority. Thus, teachers must acquire urgent first aid training through more advanced teaching strategy to keep students' safe and healthy throughout the school day. ${ }^{[5]}$

\subsection{Literature review}

Although the epidemiology of childhood injuries has been well studied in many developed countries, there are still only a few studies done on parental and teachers' knowledge and skills concerning childhood injury. ${ }^{[1]}$ Recent studies have been emphasized that administering appropriate first aid to students soon after the injuries will save their lives and promote their health. Early and appropriate treatment of such emergencies can help reduce morbidity and mortality. ${ }^{[4]}$ In that case proficient and skillful first aid mangers are a priority. Consequently, teachers must acquire first aid training programs based on an illustrating proper teaching methods. ${ }^{[5,6]}$

Video modeling is a strategy involving the use of videos to provide modeling of targeted skills. ${ }^{[7]}$ Video technology is used in clinical instruction for acquisition of technical skills and training staff in emergency procedures like resuscitation, tracheal intubations and other emergency medical situations that require urgent first aid management. Also, video conferencing plays an important role in educational process. ${ }^{[8]}$ Further, video materials provide a unique opportunity to present, teach, and internalize authentic information, linguistic, cultural, and visual about the target subject. Because these materials can be edited for presentation, they are also excellent venues for focusing our learners' attention on specific details and for creating exercise materials based on the video itself. In short, judicious use of this material can substantially increase the quantity and quality of time spent on task with the emphasis on knowledge and skills for effective practice. ${ }^{[7]}$ Teaching by videos has many benefits for the learners as it makes them more familiar with the nature of the skills. Also, while doing practical, there remains no necessity for explaining except educating precautions. This method proves more useful if the learners are told before that they are going to do practical re-demonstration of the previously learned skills. ${ }^{[8]}$ Consequently, the present study aimed to assess the effect of video assisted teaching method versus traditional lecture on primary teachers' knowledge and skills regarding first aids management of children' school day accidents.

\subsection{Aim of the study}

To assess the effect of video assisted teaching method versus traditional lecture on primary teachers' knowledge and skills regarding first aids management of children' school day accidents.

\subsection{Research hypothesis}

Primary school teachers who receive first aid measures by video assisted teaching method will be knowledgeable and skilful in the management of children' school day accidents compared to who exposed to traditional lecture.

\section{MeTHODS}

\subsection{Design}

A Comparative research design was utilized.

\subsection{Settings}

The study was conducted in four primary schools at Menoufia Governerate:

(1) El-Ahmadia primary school

(2) El-Sayida- Kadiga primary school

(3) El-Shaheed Abdel Moneim Riad primary school

(4) El-Shohadaa primary school.

Technique of school selection: All names of the primary schools at Menoufia governorate were put in a bowl then randomly drawing out four of them was done.

\subsection{Participants}

A simple random sample of 200 primary school teachers was utilized. All names of the teachers at every primary school were put also in a bowl, and then randomly drawing out a number of 50 teachers from each school of the previously mentioned settings was done.

\section{Sample size}

From population size 7,000 (number of teachers of primary schools at Menoufia Governorate), a sample size was calculated by using Epi Info ${ }^{\mathrm{TM}} 7$ technique rendered 200 participants as a sample for this study at two sided confidence level $95 \%$, power $80 \%$, margin of error accepted $5 \%$ and $20 \%$ 
response distribution rate for planned program on knowledge and skills regarding first aid in selected conditions among primary school teachers according to 9 Maloti. ${ }^{[9]}$

In terms of the numbers that selected above, the sample size $\mathrm{n}$ and margin of error $\mathrm{E}$ are given by

$$
\begin{aligned}
& x=Z(c / 100)^{2} r(100-r) \\
& n=N x /\left[(N-1) E^{2}+x\right] \\
& E=\sqrt{(N-n) x / n(N-1)}
\end{aligned}
$$

Where $N$ is the population size, $r$ is the fraction of responses that you are interested in, and $Z(\mathrm{c} / 100)$ is the critical value for the confidence level.

\subsection{Data collection tools}

The researcher developed the data collection tools after extensive review of the literature related to first aid measures and using video assisted teaching method in management of children's school day accidents $v s$. traditional lecture. It included two constructed tools.

Tool one: C Teachers' knowledge questionnaire: It consisted of two parts:

Part one: A structured: socio-demographic questionnaire to obtain demographic data of the studied subjects.

Part two: Structured knowledge questionnaire regarding first aids measures. It consisted of questionnaire related to first aids of wounds and injuries, bleeding of the gums, epistaxis, foreign body of the eye and ear, chocking, cardiopulmonary resuscitation, etc.

Tool two: Five points Likert- scale structured performance check list was used to assess degree of improvement in primary school teachers' management skills regarding first aids for children' school day accidents after utilization of Videoassisted teaching method versus Lecture Method. It included 37 items that divided into 5 major headlines: teacher management of wounds, teacher management of epistaxis, teacher management of fracture, teacher management of choking, and cardio pulmonary resuscitation.

\subsection{Reliability of the tools}

Reliability was applied by the researcher for testing the internal consistency of the tool, by administration of the same tools to the same subjects under similar conditions on one or more occasions. Answers from repeated testing were compared (Test-re-test reliability $=0.7$ ).

\subsection{Validity of the tools}

They were tested for content validity by jury of five experts in the filed of Community Health Nursing and Pediatric Spe- cialty to ascertain relevance and completeness.

\subsection{Data collection}

Data was collected at the end first of August 2013 to 25 November 2014. An official letters were issued from the Faculty of Nursing Menofia University, and send to the directors of all the selected schools after explanation of the aim of the study to get their permission.

\subsection{Ethical consideration}

A written consent was obtained from teachers to participate in the study. During the initial interview the purpose of the study was explained. Participants were assured that all information would be confidential and their participation in the study was voluntary without any costs and they have the right to refuse to participate in the study. Also, a written approval was obtained from an ethic committee at faculty of nursing, Menoufia University, Egypt.

\subsection{Pilot study}

The pilot study was conducted on 20 primary school teachers who were excluded from the total sample size. Based on the findings of the pilot study, the necessarily modifications were done accordingly and some items were added, such as the first aid measures related to fracture, gum bleeding and insects bites.

\subsection{Procedure of data collection Implementation of the program}

This study hypothesized that Primary school teachers who receive first aid measures by video assisted teaching method will be knowledgeable and skilful in the management of children' school day accidents compared to who exposed to traditional lecture. This was achieved through 12 specific sessions with a number of six sessions for each group (25 subjects) to present the first aid measures for management of common accidents for primary school children by traditional lecture for the first group and through video assisted teaching strategy for the second group in every school setting.

Primarily, the purpose of the study was explained and the subjects' consent to participate was obtained. Also, they were informed about the schedule time and place of training. According to schools' schedule time participants in each school (50 subjects) were divided into two equal groups. Structured sessions about first aid management of children's school day accidents through video teaching strategy Vs traditional lecture were implemented three times weekly with a total number of 6 sessions for each group (25 subjects) within two weeks to assume 16 weeks for all subjects in the four selected settings. 
In each school the first group (25 subjects) was given a traditional lecture about first aid management of common accidents of children during school day for two weeks. Also, they were given a learning booklet containing the same knowledge. The second group (25subjects) was given also the same information by video assisted teaching method and the same learning booklet within the second two weeks. The subjects asked to fill the structured knowledge questionnaire regarding first aids measures of common children injuries for about 30 minutes, and 45 minutes for each participant to be observed for re-demonstration of all the procedures that were involved in the observational checklists after utilization of the two teaching methods at the last two sessions consequentially.

\section{Presentation using traditional lecture related items of} first aids through data-show: The researcher presented a lecture related to first aid of children common injuries during their school day by a traditional lecture for the first group. The researcher asked the subjects to re-demonstrated procedures as they taught through the lecture.

Presentation of High-Definition videos related items of first aids: The researcher presented videos via the researcher's lab top through data-show for the second group only. Also, the researcher asked the subjects to redemonstrated procedures as they seen via videos demonstration. The researcher gave copies of the procedures on CDs to the teachers at the end of the data collection.

High-Definition videos were adopted from different internet sites. The content of videos included the following: One video about management of fracture ( 3 minutes, 11 seconds). ${ }^{[10]}$ two videos about management of choking (1 minute, 26 seconds) $)^{[11]}$ and (1 minute, 8 seconds). ${ }^{[12]}$ One video about management of burn (7 minutes, 39 seconds). ${ }^{[13]}$ One video about management of epistaxis (1 minute, $39 \mathrm{sec}$ onds). ${ }^{[14]}$ Two videos about artificial respiration and cardio pulmonary resuscitation (1 minute, 13 seconds) ${ }^{[15]}$ and (1 minutes). ${ }^{[16]}$

\subsection{Statistical analysis}

The data was collected and entered into the personal computer. Statistical analysis was done using Statistical Package for Social Science (SPSS/version 20) Quantitative data were expressed as mean \& standard deviation (X $\pm \mathrm{SD})$ and analyzed by applying student $t$ test for comparison of two groups of normally distributed variables and two groups of not normally distributed variables by applying Mann-Whitney Test. Qualitative data were expressed as number and percentage. $P$-value at .05 was used to determine level of significance.

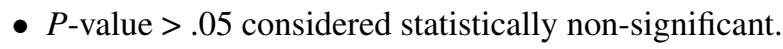

- $P$-value $\leq .05$ considered statistically significant.

- $P$-value $\leq .001$ considered highly statistically significant.

\section{RESULTS}

Table 1 showed distribution of sociodemographic characteristics of the studied sample. It was noticed that, most of the subjects $36.0 \%$ and $37.0 \%$ who undergone first aid by lecture and video assisted teaching method consequently were in age group 30-35 years old. The mean age (SD) was 30.93 (5.10). In relation to sex, the majority of the subjects $62.0 \%$ and $49.0 \%$ were male. Concerning their marital status, $83.0 \%$ and $71.0 \%$ consequently were married. Also, it was estimated that, $66.0 \%$ and $60.0 \%$ of the studied sample had higher education. Regarding years of experience, $33.0 \%$ and $45.0 \%$ of the subjects had experienced less than one year in primary education. Unfortunately, the majority of the subjects who trained on first aid by lecture method and video assisted teaching method $(88.0 \%)$ and $(91 \%)$ respectively did not attend any previous training courses about first aid.

Table 2 illustrated mean, mean percentage and SD of knowledge variables concerning first aid for selected children's accidents through lecture method Vs video assisted teaching methods. It was observed that, the mean knowledge score of lecture method was $(12.77 \pm 5.00)$ compared to $(28.68$ \pm 3.77 ) of video-assisted teaching method. Also, there was highly statistical significant improvement in all knowledge variables of primary school teachers who receive first aids by video-assisted teaching method where $P<.001$.

Table 3 clarified frequency and percentage distribution of knowledge variables concerning first aid for selected children's accidents through lecture method vs. video assisted teaching methods. It was oblivious that, the percentage distribution of total knowledge score of primary school teachers who receive first aids by lecture method Vs video-assisted teaching method was $(67.0 \%$ poor, $33.0 \%$ fair, and $0.0 \%$ good) compared to (4.0\% poor, $54.0 \%$ fair and $42 \%$ good) respectively. A highly statistical significant improvement in all knowledge variables of primary school teachers who receive first aids by video-assisted teaching method was noticed where $P<.001$.

Table 4 showed the distribution of total practice score of the studied sample regarding first aid of children's school day accidents. The present study clarified that, there was statistical significant improvement in total practice score of the studied group who undergone Video-assisted teaching method Compared to the studied group who undergone lecture method regarding first aid of common students' school day accidents. 
Table 1. Sociodemographic characteristics of the studied sample $(n=200)$

\begin{tabular}{|c|c|c|c|c|c|}
\hline \multirow{2}{*}{ Sociodemographic characteristics } & \multicolumn{2}{|c|}{ Lecture method $(n=100)$} & \multicolumn{2}{|c|}{ Video-assisted teaching method $(n=100)$} & \multirow{2}{*}{ Statistics } \\
\hline & No. & $\%$ & No. & $\%$ & \\
\hline \multicolumn{6}{|l|}{ Age (years): } \\
\hline $20<25$ & 8 & 8.0 & 11 & 11.0 & $\chi^{2}=0.66$ \\
\hline $25<30$ & 32 & 32.0 & 29 & 29.0 & $\stackrel{\tilde{P}}{\mathrm{P}}=.88$ \\
\hline $30<35$ & 36 & 36.0 & 37 & 37.0 & NS \\
\hline 35 and above & 24 & 24.0 & 23 & 23.0 & \\
\hline Range & \multicolumn{2}{|c|}{$22.00-45.00$} & \multicolumn{2}{|c|}{$21.00-40.00$} & $T=0.24$ \\
\hline Mean \pm SD & \multicolumn{2}{|c|}{$31.09 \pm 4.11$} & \multicolumn{2}{|c|}{$30.93 \pm 5.10$} & $\begin{array}{l}P=0.81 \\
\text { NS }\end{array}$ \\
\hline Sex: & & & & & $\chi^{2}=2.92$ \\
\hline Male & 62 & 62.0 & 49 & 49.0 & $\stackrel{P}{P}=.09$ \\
\hline Female & 38 & 38.0 & 51 & 51.0 & NS \\
\hline \multicolumn{6}{|l|}{ Level of education: } \\
\hline Medium degree & 27 & 27.0 & 31 & 31.0 & $\chi^{2}=0.96$ \\
\hline Associated degree & 66 & 66.0 & 60 & 60.0 & $\stackrel{\tilde{P}}{\mathrm{P}}=.81$ \\
\hline High education & 4 & 4.0 & 6 & 6.0 & NS \\
\hline Post graduate studies & 3 & 3.0 & 3 & 3.0 & \\
\hline \multicolumn{6}{|l|}{ Years of experience: } \\
\hline$<1$ year & 33 & 33.0 & 45 & 45.0 & $\chi^{2}=3.73$ \\
\hline $1-5$ years & 38 & 38.0 & 27 & 27.0 & $\stackrel{N}{P}=.15$ \\
\hline $5-10$ years & 29 & 29.0 & 28 & 28.0 & NS \\
\hline \multicolumn{5}{|l|}{ Attending training courses on first aid: } & $\chi^{2}=0.21$ \\
\hline Yes & 12 & 12.0 & 9 & 9.0 & $\stackrel{\Re}{P}=.64$ \\
\hline No & 88 & 88.0 & 91 & 91.0 & NS \\
\hline
\end{tabular}

Note. NS: $P>.05$

Table 2. Mean, mean percentage and SD of knowledge variables concerning first aid for selected children's accidents through lecture method $v s$. video assisted teaching methods

\begin{tabular}{|c|c|c|c|c|}
\hline Knowledge variables & Maximum score & Mean & Mean percentage & SD \\
\hline $\begin{array}{l}\text { General Information about the child first aid: } \\
\text { L.M } \\
\text { VAT.M } \\
P \text { value ** }\end{array}$ & $\begin{array}{l}5 \\
5 \\
<.001\end{array}$ & $\begin{array}{l}2.13 \\
3.91\end{array}$ & $\begin{array}{l}42.6 \\
78.2\end{array}$ & $\begin{array}{l}1.13 \\
0.82\end{array}$ \\
\hline $\begin{array}{l}\text { First aid on wound and injury: } \\
\text { L.M } \\
\text { VAT.M } \\
P \text { value* }\end{array}$ & $\begin{array}{l}14 \\
14 \\
<.001\end{array}$ & $\begin{array}{l}4.95 \\
9.07\end{array}$ & $\begin{array}{l}35.4 \\
64.8\end{array}$ & $\begin{array}{l}1.59 \\
1.35\end{array}$ \\
\hline $\begin{array}{l}\text { First aid for gum bleeding \& epistaxis: } \\
\text { L.M } \\
\text { VAT.M } \\
P \text { value** }\end{array}$ & $\begin{array}{l}4 \\
4 \\
<.001\end{array}$ & $\begin{array}{l}0.72 \\
2.40\end{array}$ & $\begin{array}{l}18 \\
60.0\end{array}$ & $\begin{array}{l}0.73 \\
0.65\end{array}$ \\
\hline $\begin{array}{l}\text { First aid for cases of fainting: } \\
\text { LM } \\
\text { VATM } \\
P \text { value** }\end{array}$ & $\begin{array}{l}2 \\
2 \\
<.001\end{array}$ & $\begin{array}{l}0.77 \\
1.38\end{array}$ & $\begin{array}{l}38.5 \\
69.0\end{array}$ & $\begin{array}{l}0.81 \\
0.52\end{array}$ \\
\hline $\begin{array}{l}\text { First aid for epilepsy: } \\
\text { LM } \\
\text { VATM } \\
P \text { value** }\end{array}$ & $\begin{array}{l}2 \\
2 \\
<.001\end{array}$ & $\begin{array}{l}0.50 \\
1.67\end{array}$ & $\begin{array}{l}25.0 \\
83.5\end{array}$ & $\begin{array}{l}0.59 \\
0.49\end{array}$ \\
\hline $\begin{array}{l}\text { Cardiopulmonary arrest: } \\
\text { LM } \\
\text { VATM } \\
P \text { value** }\end{array}$ & $\begin{array}{l}2 \\
2 \\
<.001\end{array}$ & $\begin{array}{l}0.61 \\
1.36\end{array}$ & $\begin{array}{l}30.5 \\
68.0\end{array}$ & $\begin{array}{l}0.64 \\
0.73\end{array}$ \\
\hline $\begin{array}{l}\text { First aid for the case of Fracture: } \\
\text { LM } \\
\text { VATM } \\
P \text { value** }\end{array}$ & $\begin{array}{l}1 \\
1 \\
<.001\end{array}$ & $\begin{array}{l}0.25 \\
0.80\end{array}$ & $\begin{array}{l}25.0 \\
80.0\end{array}$ & $\begin{array}{l}0.43 \\
0.40\end{array}$ \\
\hline $\begin{array}{l}\text { First aid for choking case: } \\
\text { LM } \\
\text { VATM } \\
P \text { value** }\end{array}$ & $\begin{array}{l}1 \\
1 \\
<.001\end{array}$ & $\begin{array}{l}0.23 \\
0.79\end{array}$ & $\begin{array}{l}23.0 \\
79.0\end{array}$ & $\begin{array}{l}0.42 \\
0.40\end{array}$ \\
\hline $\begin{array}{l}\text { Total knowledge score: } \\
\text { L.M } \\
\text { VAT.M } \\
P \text { value** }\end{array}$ & $\begin{array}{l}41 \\
41 \\
<.001\end{array}$ & $\begin{array}{l}12.77 \\
28.68\end{array}$ & $\begin{array}{l}31.1 \\
70.0\end{array}$ & $\begin{array}{l}5.00 \\
3.77\end{array}$ \\
\hline
\end{tabular}

Note. L.M= Lecture Method; VAT.M= Video-assisted teaching method 
Table 3. Frequency and percentage distribution of knowledge variables concerning first aid for selected children's accidents through lecture method $v s$. video assisted teaching methods

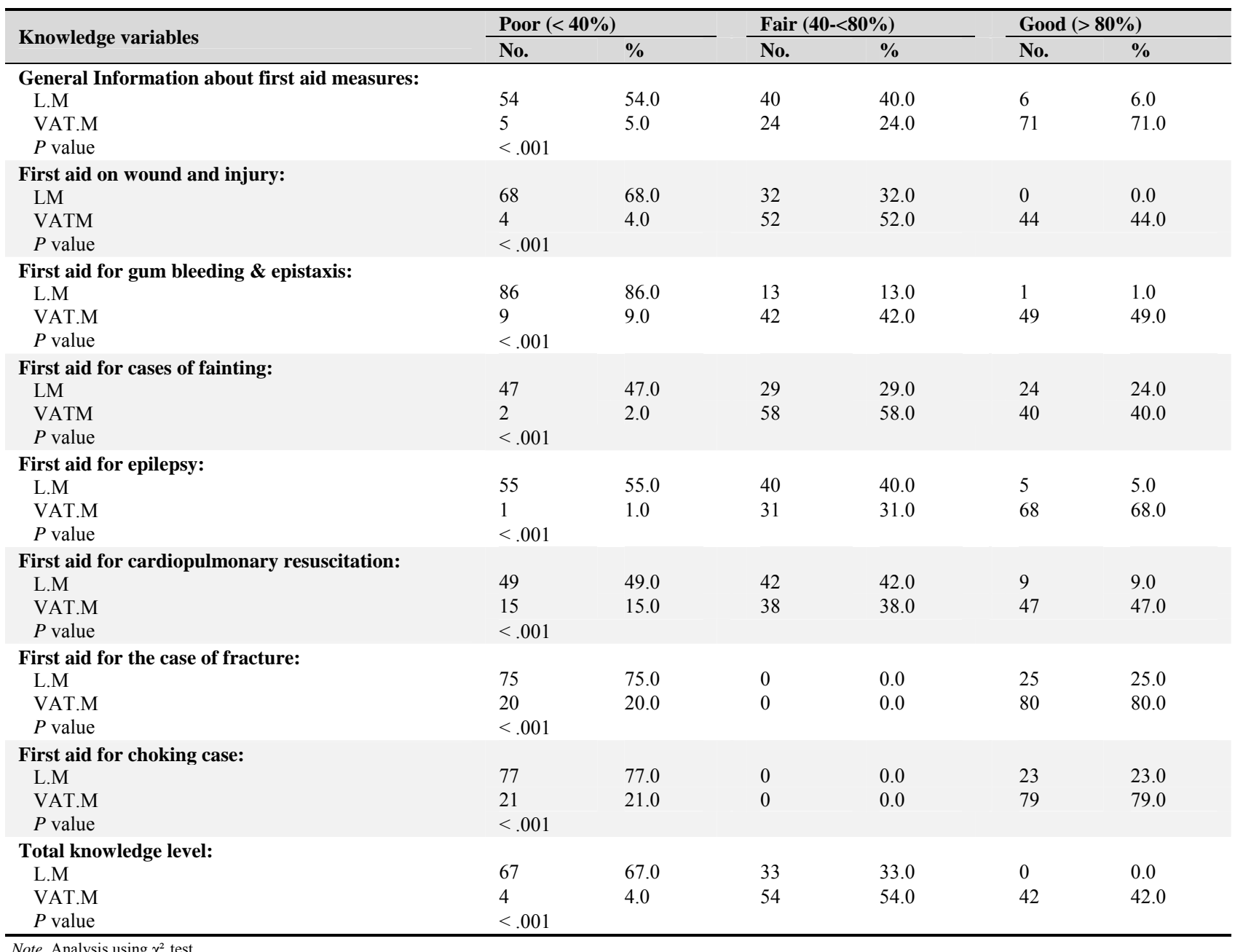

Note. Analysis using $\chi^{2}$ test

Table 4. Distribution of total practice score of the studied sample regarding first aid management of selected students' school day accidents

\begin{tabular}{|c|c|c|c|}
\hline Total practice score of the studied sample & $\begin{array}{l}\text { Lecture method } \\
(\mathrm{n}=100)\end{array}$ & $\begin{array}{l}\text { Video-assisted teaching method } \\
(\mathrm{n}=100)\end{array}$ & Statistics \\
\hline Wound: (total score = 24) & & & $t=52.61$ \\
\hline Range & $7.00-11.00$ & $15.00-23.00$ & $P<.001$ \\
\hline Mean \pm SD & $8.95 \pm 0.88$ & $19.87 \pm 1.88$ & HS \\
\hline Epistaxis: (total score $=28$ ) & & & $t=40.10$ \\
\hline Range & $9.00-13.00$ & $17.00-28.00$ & $P<.001$ \\
\hline Mean \pm SD & $10.45 \pm 0.92$ & $23.88 \pm 3.22$ & HS \\
\hline Fracture: (total score $=16$ ) & & & $t=51.92$ \\
\hline Range & $5.00-8.00$ & $10.00-16.00$ & $P<.001$ \\
\hline Mean \pm SD & $6.33 \pm 0.72$ & $13.82 \pm 1.25$ & HS \\
\hline Choking: (total score $=48$ ) & & & $t=47.18$ \\
\hline Range & $14.00-23.00$ & $29.00-46.00$ & $P<.001$ \\
\hline Mean \pm SD & $18.28 \pm 2.03$ & $38.98 \pm 3.89$ & HS \\
\hline Cardio pulmonary resuscitation: (total score = 28) & & & $t=43.94$ \\
\hline Range & $7.00-16.00$ & $18.00-27.00$ & $P<.001$ \\
\hline Mean \pm SD & $10.82 \pm 1.59$ & $22.89 \pm 2.24$ & HS \\
\hline Total score of Teachers' Practices: (total score $=144$ ) & & & $t=61.08$ \\
\hline Range & $46.00-69.00$ & $93.00-135.00$ & $P<.001$ \\
\hline Mean \pm SD & $54.83 \pm 4.03$ & $119.44 \pm 9.78$ & HS \\
\hline
\end{tabular}


Figures 1 showed the distribution of total knowledge score of the studied sample regarding first aid of selected children's conditions by lecture methods vs. video-assisted teaching method. The present study clarified that, there was statistical significant improvement in total mean knowledge score of the studied subjects who undergone Video-assisted teaching method (28.68) compared to (12.77) who undergone lecture method regarding first aid of selected children's conditions.

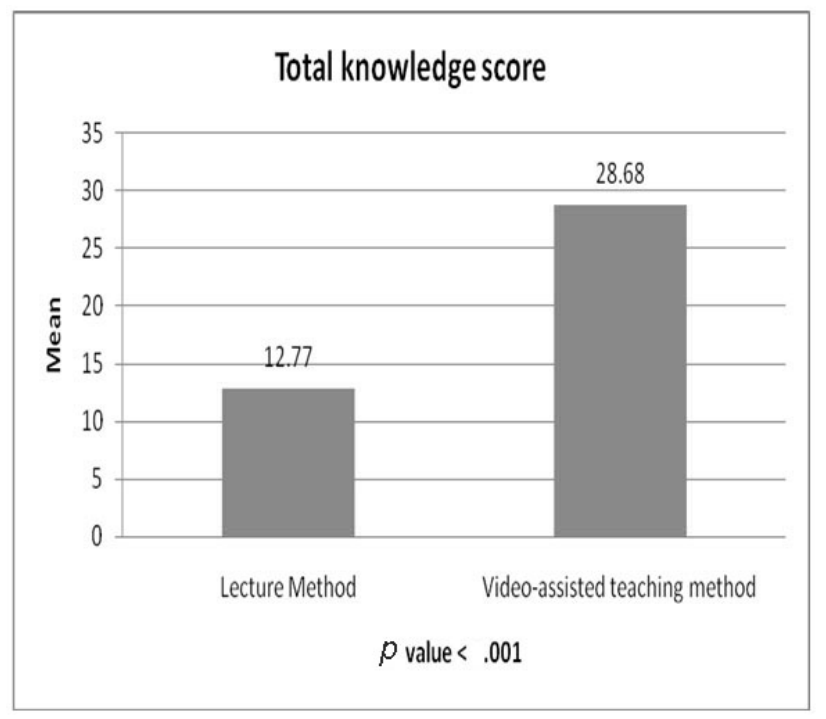

Figure 1. Distribution total knowledge score of the studied sample regarding first aid of selected children's condition by lecture methods $v s$. video-assisted teaching method HS: $P<.001$

Figures 2 indicated the distribution of total knowledge level of the studied sample regarding first aid of selected children's conditions by lecture methods $v s$. video-assisted teaching method. The present study indicated that, more than half of the primary school teachers $(67.0 \%)$ who undergone lecture method had poor knowledge level compared to (43.0\%) who undergone video-assisted teaching method had good knowledge level. There was a highly statistical significant difference was found between lecture method and videoassisted teaching method in improving knowledge level of the studied sample regarding first aid of students' school day accidents where $p=.001$.

\section{Discussion}

Primary school children constitute a major category of the total population in Egypt and worldwide. They are exposed to injuries and accidents due to curiosity, lack of experience and increased mobility. Day care institutions for these children increased nowadays. The primary school teacher has crucial role in caring for primary school children through supervision and prevention of health hazards. Also, they should be well trained on first aid and emergency control to save children lives. ${ }^{[4]}$ Video materials provide a unique opportunity to present, teach, and internalize authentic information, linguistic, cultural, and visual about the target subject. ${ }^{[17]}$ So, the present study aims to assess the effect of a video assisted teaching method versus traditional lecture on primary teachers' knowledge and skills regarding first aids management of children' school day accidents.

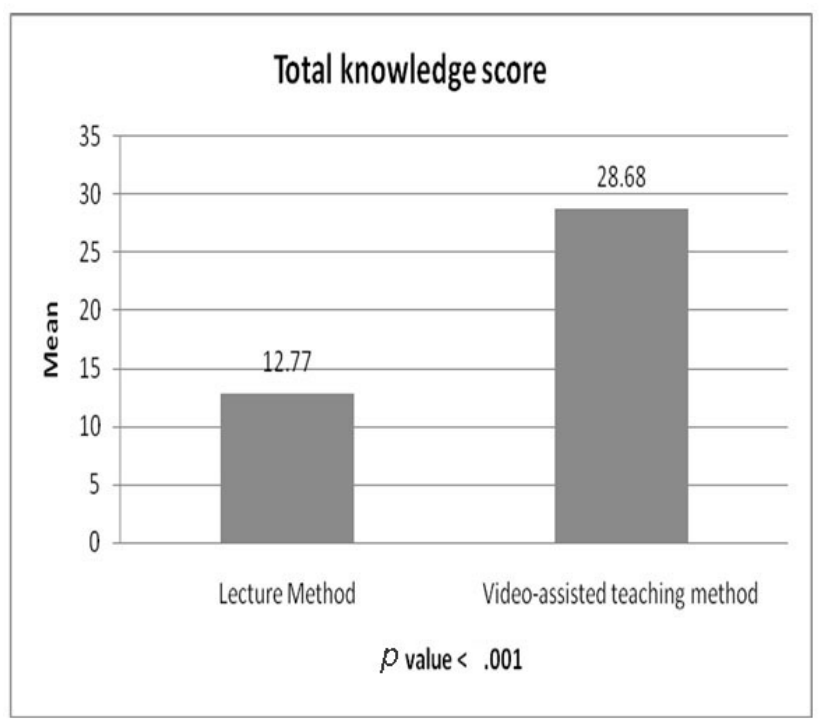

Figure 2. Distribution total knowledge level of the studied sample regarding first aid of selected children's condition by lecture methods $v s$. video-assisted teaching method HS: $P<.001$

The result of the present study covered six main areas as follows: firstly, socio-demographic characteristic of the studied subjects; secondly, mean, mean percentage and SD of knowledge variables of the studied subjects; thirdly, frequency and percentage distribution of knowledge variables of the studied subjects; fourthly, Distribution of total practice score of the studied sample; fifthly, distribution of total knowledge score of the studied sample; lastly, distribution of total knowledge level of the studied sample.

Concerning, distribution of sociodemographic characteristics of the studied sample. In relation to attending training courses on first aid: the present study revealed that, the highest percentage of the studied sample didn't attend any training courses. The result comes in agreement with Maloti ${ }^{[9]}$ who conducted a study to assess effectiveness of structured teaching module on first aid among teachers. He reported that, the minority of teachers had not any exposure to inservice education related to first aid.

Regarding, mean, mean percentage and SD of knowledge variables concerning first aid for selected children's accidents 
through lecture method $v$ s. video assisted teaching methods of the studied subjects. It was observed that, highly statistical significant difference was found between mean knowledge score of studied subjects who undergone first aid through lecture method vs. video-assisted teaching method. Also, there was highly statistical significant improvement in all knowledge variables of primary school teachers who receive first aids by video-assisted teaching method.

This result comes in agreement with Bener et al. ${ }^{[18]}$ who conducted a study to assess effectiveness of two teaching strategies (lecture and video presentation) in selected health problems of primary school children's among primary school teachers in Bangalori. The results revealed that, the utilized teaching strategies increased knowledge score of the primary school teachers. Also, his result indicated significant increase in knowledge level of the subjects who undergone video assisted teaching than the subjects who undergone lecture only. The result of the current study was expected because the subjects who receive first aid sessions by video-assisted teaching method acquired knowledge and skills through observation and listening rather than listening only by lecture teaching method.

Also, this finding is similar to what was reported by Nikopoulou \& Nikopoulos et al. ${ }^{[19]}$ who evaluated the impact of video-based versus traditional lectures on student learning at United Kingdom. The authors reported that all students demonstrated a slight superiority of video-based lectures over traditional ones with remarkable increase of correct responses from an average of $15.5 \%$ during baseline to an average of $60 \%$ during intervention was recorded for the quizzes that video-based lectures were designed for, irrespectively of the topic. Moreover, a similar finding was reported by Rajesh \& Swamy ${ }^{[20]}$ who assessed the effectiveness of video-assisted teaching program on knowledge regarding non-pharmacological pain relieving intervention for children among Indian staff nurses in selected hospital, and reported that the video assisted teaching program was significantly effective in improving the knowledge of the staff nurses regarding non-pharmacological pain relieving intervention for children. Those results may be contributed to prove the best effect of using video technology in teaching.

Further, the finding of the present study is supported by Sunikumari ${ }^{[21]}$ who conducted a study to evaluate the effectiveness of lecture demonstration versus video-assisted teaching on knowledge and practice of breastfeeding technique among primipara in Pune city, India. A comparative study was done on 60 samples. 30 samples received lecture on breast feeding technique and 30 samples are provided videoassisted teaching, after pre-test. On 7 days after posttest was administered, finding revealed that there is significant difference in knowledge scores between lecture demonstration and video-assisted teaching. Moreover, similar finding was reported by Connolly \& colleagues ${ }^{[22]}$ who demonstrated basic life support in schools in Northern Ireland through video-assisted teaching and found that, children showed a highly significant increase in level of knowledge and practice following the well designed training session.

Regarding, frequency and percentage distribution of knowledge variables concerning first aid for selected children's accidents through lecture method $v s$. video assisted teaching methods. It was noticed that, the percentage distribution of total knowledge score of primary school teachers who receive first aids by video-assisted teaching method was higher than percentage distribution of total knowledge score of studied subjects who receive first aid through lecture method. Also, there was highly statistical significant improvement in all knowledge variables of primary school teachers who receive first aids through video-assisted teaching method. These finding is supported by Mahmoud \& Elsayed ${ }^{[23]}$ who designed and implemented a first aid program using video teaching method for employee's female health colleges at Najran University in Saudi Arabian. The study's authors reported that, there was a significant statistical difference in participants' total knowledge score regarding first aid before and immediately after the implementation of the program ( $p$ $=.000)$ and also between immediately after the implementation of the program and after 6 months on follow up ( $p=$ $.002)$.

Also, this finding is similar to what was reported by Prabhu ${ }^{[24]}$ who performed a study for a comparison of traditional versus video based teaching on neurological assessment among undergraduate Indian nursing students. He reported that, video based teaching was effective in improving knowledge and skill of undergraduate nursing students on neurological assessment. Indeed, this actually reflect that video teaching material considered one of the best teaching strategies in teaching first aid measures.

As regard to distribution of total practice score of the studied sample regarding first aid management of selected children' s school day accidents. The present study clarified that, there was statistical significant improvement in total practice score of the studied group who undergone Video-assisted teaching method compared to the studied group who undergone lecture method regarding first aid of common students' school day accidents. The current result is consistent with Ergenekona $^{[25]}$ who examined teaching basic first-aid skills regarding home accidents of children with autism through video modeling in Turkish primary schools. The author re- 
ported that, the first aid skills training package which consists of reading a story, forming a simulation situation related to the target behavior and watching the video about the simulation was found to be effective in teaching basic first-aid skills to children with autism.

In addition, a similar study was conducted by Mehrpour et al. ${ }^{[26]}$ who examined the effect of using a supplemental video teaching tool on enhancing splinting skills between two groups of medical students from three universities hospitals at Tehran and Iran. The study's results revealed that the participants in the educational video group performed substantially better than the students in the traditional teaching group. Moreover, similar finding was reported by Friedman $^{[27]}$ who examined the effect of video-assisted structured teaching on improving aseptic technique skills among two groups of Canadian medical students. The study results demonstrated a significant improvement in aseptic technique of the two studied groups after utilization of video intervention, which reflects, Video teaching has been shown to be a valuable tool in improving performance.

In relation to, distribution of total knowledge score and total knowledge level of the studied sample regarding first aid of selected children's conditions by lecture methods Vs videoassisted teaching method. The present study clarified that, there were statistical significant improvement in total mean knowledge score and total knowledge level of the studied subjects who undergone Video-assisted teaching method. This result supported by Gagiliardi et al. ${ }^{[28]}$ who studied first aid training and emergency care by video methods on 250 public school teachers. The study results indicated that, the majority of the subjects were shown significant improvement in their knowledge score and knowledge level.
Also, the finding of the current study supported by Al Ham$\operatorname{mad} \&$ Salama ${ }^{[29]}$ who evaluated the effectiveness of infant oral health care educational intervention, in the form of a power point and video presentation in King Saudi University in Riyadh city. The authors reported that, the study participants demonstrated greater interest and increased knowledge concerning maintenance of infant oral health through video presentation. The findings of the current study are expected because teaching first aid through visual teaching methods was shown to increase acquisition of information and improve accuracy of skills through utilization of many senses. So, it is approved that, video assisted teaching is more effective than other traditional teaching strategies in improving learners' knowledge and skills.

\section{Conclusions}

It was concluded that, there was a statistical significant improvement in total knowledge score, total knowledge level and first aid management skills of primary school teachers undergoing video-assisted teaching method concerning first aid of children's school day accidents. Consequently, utilization of video-assisted teaching method was succeeded in achieving significant improvements in the primary school teachers' knowledge and management skills regarding first aids for children's school day accidents compared to traditional lecture method.

\section{Recommendations}

The study recommended to importantly utilizing videoassisted teaching strategy in teaching first aid measures to promote children's health and improve knowledge and skills of their caregivers.

\section{Conflicts of InTERest Disclosure}

The authors declare that there is no conflict of interest.

\section{REFERENCES}

[1] Thein MM, Lee BW, Bun PY. Knowledge, attitude and practices of childhood injuries and their prevention by primary caregivers in Singapore. Singapore Med J. 2005; 46: 122-26. Available from: http://www.journalagent.com/z4/download_f ulltext . asp?pdir=atuder\&plng=eng\&un=ATUDER-00719 PMid:15735876

[2] El-Sayed H, Zekry O, Abdel Hamid S, et al. Pattern and severity of childhood unintentional injuries in Ismailia city, Egypt. African Safety Promotion Journal. 2012; 10(2).

[3] Ekman R, Svanstrom L, Langberg B. Temporal trends, gender, and geographic distributions in child and youth injury rates in Sweden. Inj Prev. 2005; 11: 29-32. Available from: http://www.researchgate.net/publication
/44674553_Trends_in_childhood_trauma_mortality _in_the_fast_economically_developing_State_of_ Qatar/file/9c960521e441e8d135.pdfPMid: 15691986 http://dx.doi.org/10.1136/ip.2003.005074

[4] Singer AJ, Gulla J, Thode HC, et al. Pediatric first aid knowledge among parents. Pediatr Emerg Care. 2004; 20: 808-11. http: //dx.doi.org/10.1097/01.pec.0000148028.53598.5c

[5] Başer M, Çoban S, Taşçı S. Evaluating First-aid Knowledge and Attitudes of a Sample of Turkish Primary School Teachers. Journal of Emergency Nursing. 2007; 33(5): 428-432. PMid:17884471 http://dx.doi.org/10.1016/j.jen.2006.11.003

[6] Lubrano R, Romero S. How to become an under 11 rescuers: a practical method to teach first aid to primary schoolchildren. Resuscitation. 2005; 64(3): 303-7. Available from: http://jee.erciyes.ed 
u.tr/resources/hirca-JEE-2-1.pdf PMid:15733758 http: //dx.doi.org/10.1016/j.resuscitation.2004.09.004

[7] Bellini S, Akullian J. A metaanalysis of video modeling and video self-modeling interventions for children and adolescents with autism spectrum disorders. Exceptional Children. 2007; 73: 264-287. http: //dx.doi.org/10.1177/001440290707300301

[8] Fakhry A, Cooper S, Salach N. Video assisted clinical instruction in dentistry, department of pridontics, college dentistry, university of Lowa, USA. Eur J Dental Educ. 2007. Available from: http://119.82.96.198:8080/jspui/bitstream/123 456789/1450/1/CDNNPAE00016.pdf

[9] Maloti D. Effectivness of a planed teaching program on knowledge regarding first aid on selected condition among primary school teachers working at Nagar Bangaliori Communit. Community health nursing. 2006; 1-36.

[10] Medial Staff's Apolloho Hospitals. First Aid for Broken Bones. 2013. Available from: https://r6---sn-uxaxjvhxbt2u-j5pd.goog levideo.com/videoplayback?lmt

[11] Australian Rescuscitation Council, AVRU and ASCIA. A practical Guide to Baby and Child First Aid. 2013. Available from: https://r5---sn-uxaxjvhxbt2u-j5pe.googlevideo. com/videoplayback?fexp

[12] British Red Cross. First Aid Cjoking Baby. Mybirth. 2013. Available from: https://r4---sn-uxaxjvhxbt2u-j5pd.googlevideo. com/videoplayback? itag=160\&mime=video\%2Fmp4\&expire

[13] Medical Surgical Nursing's Staff. Nursing Management for Acute Care of Burns. Southern Union State Community College. Nursing Practice. 2013; 3: 100-106.

[14] British Red Cross. Children First Aid Nosebleed. 2012. Available from: https://r2---sn-hpa7ln7y.googlevideo.com/vide oplayback?gir=yes\&sver $=3 \& p$

[15] Williams M. How to Perform CPR. CPR Ccertified.comINDIGOMedical Training. Available from: https://r2---sn-uxaxjvhxbt2u1A2CD53788CE7E03F 137A25FDDB8B40D087\&clen=4078446\&pl=20\&mv=m\&mt

[16] Birnbaumer D. Infant \& Todder CPR. Surviving Infancy. 2012.

[17] Roaten JB, Partrick DA, Nydam TL, et al. Nonaccidental trauma is a major cause of morbidity and mortality among patients at a regional level 1 pediatric trauma center. J Pediatr Surg. 2006; 41 : 2013-2015. PMid:17161194 http://dx.doi.org/10.1016/j.j pedsurg. 2006.08.028

[18] Bener A, Hyder AA, Schenk E. Trends in childhood injury mortality in a developing country: United Arab Emirates. Accid Emerg Nurs. 2007; 15: 228-233. PMid:17920269 http://dx.doi.org/10.10 $16 / \mathrm{j}$. aaen . 2007.07.010
[19] Nikopoulou-Smyrni P, Nikopoulos C. Evaluating the Impact of VideoBased Versus Traditional Lectures on Student Learning. Educational Research. 2010; 1(8): 304-311.

[20] Rajesh S, Swamy AA. Effectiveness of Video Assisted Teaching Programme on Knowledge regarding Non Pharmacological Pain Relieving Intervention for Children among Staff Nurses in Hospital. Asian Journal of Multidisciplinary Studies. 2014; 10(2): 2348.

[21] Sunikumari MS. Evaluate the effectiveness of lecture cum demonstration versus video-assisted teaching on knowledge and practice of breastfeeding technique among primipara. 2011. Available from: http://www.ajms.co.in/sites/ajms/index.php/ ajms/article/viewFile/654/543

[22] Conolly M, Toner P, Connolly D, et al. The "ABC for Life" Programme-Teaching Basic Life Support in Schools. Resuscitation. 2007; 270-9. Available from: http://applications .emro. who. int/imemrf-physician.pdf PMid:17134814 http://dx.doi .org/10.1016/j.resuscitation.2006.06.031

[23] Mahmoud HM, Elsayed MS. Designing and Implementing A first Aid Program for Employees of Female Health Colleges at Najran University. International Journal of Advanced Research. 2013; 1(9): 269-285.

[24] Prabhu S. Comparison of Traditional Versus Video Based Teaching on Neurological Assessment among Undergraduate Nursing Students. Nitte University Journal of Health Science. 2013; 3(2): 2249-7110.

[25] Ergenekona Y. Teaching Basic First-Aid Skills Against Home Accidents to Children with Autism through Video Modeling. Educational Sciences: Theory \& Practice. 2012; 12(4): 2759-2766.

[26] Mehrpour RS, Aghamirsalim M, Motamedi KS, et al. A supplemental Video Teaching Tool Enhances Splinting Skills. Lin Orthop Relat Res. 2013; 471(2): 649-654. PMid:23054528 http: //dx.doi.org/10.1007/s11999-012-2638-3

[27] Friedman Z, Siddiqui N, Mahmoud S, et al. Video-Assisted Structured Teaching to Improve Aseptic Technique during Neuraxial Block. Department of Anesthesia and Pain Management, Mount Sinai Hospital, University of Toronto. Oxford Unversity Press. British Journal of Anaesthesia. 2013; 1-5.

[28] Gagiliardi M, Neighros M, Spears C, et al. Emergency in the School Setting. Pre Hospital Disaster. 2011; 4: 222-5.

[29] Al Hammad SN, Salama SF. Effectiveness of an Infant Oral Health Care Educational Intervention on Knowledge of Dental Students. Advances in Medical Education and Practice. 2011; 2: 193-199. Available from: http://sbmu .acir/uploads/AMEP-19415-effectivene ss-of-an-infant-oral-health-care-educational.pdf 